\title{
FORMULATION AND EVALUATION OF CANDESARTAN CILEXETIL TRANSDERMAL PRONIOSOMAL GEL
}

\author{
Dr. A. Seetha Devi, Archana Pinnika*, P. Divya \\ Department of Pharmaceutics, Hindu college of Pharmacy, Guntur-522002, Andhra Pradesh, India \\ *Corresponding Author E-mail: parchana131@gmail.com
}

\begin{abstract}
:
The present work deals with the preparation of candesartan cilexetil proniosomal gel by coaservation phase separation method by using different surfactants, cholesterol and soya lecithin in 9:1:9 and 9:2:9 ratios. The prepared proniosomal gel formulations were evaluated for vesicle size analysis, surface morphological studies, encapsulation efficiency, In vitro drug release, ex vivo skin permeation studies and vesicular stability at different storage conditions. The results showed that candesartan cilexetil in all the formulations was successfully entrapped and a substantial change in release rate and an alteration in the encapsulation efficiency of candesartan cilexetil from proniosomes were observed upon varying the type of surfactant and cholesterol content. Vesicles formed with Spans were smaller in size than vesicles formed with Tweens. Encapsulation efficiency of proniosomes formed from Span 60, Span 40, Span20, and Span 80 was found high compared with proniosomes prepared from Tweens (Tween 20 and Tween 80). An optimised preparation with 9:2:9 ratio of Span 60, cholesterol and lecithin gave maximum encapsulation efficiency $(92.29 \%)$ and showed drug release $(95.89 \pm 0.26 \%)$ in a controlled manner with a flux value of $1.89 \mu \mathrm{g} / \mathrm{cm}^{2} / \mathrm{hr}$ and permeability co efficient value of $0.094 \mathrm{~cm}^{2} / \mathrm{hr}$ as compared to other compositions. No significant changes in relation to vesicle size and encapsulation efficiency were recorded after stability studies. It is evident from this study that proniosomes are a promising prolonged delivery system for candesartan cilexetil and have reasonably good stability characteristics.

Keywords: candesartan cilexetil, proniosomes, encapsulation efficiency, flux, stability.
\end{abstract}

\section{INTRODUCTION:}

Transdermal delivery of drugs through the skin to the systemic circulation provides convenient route of administration for a variety of drugs. This route is widely used as it is convenient, safe and avoids the GI incompatibility, bypassing first pass metabolism, enhanced bioavailability, decreased frequency of drug administration. Problem of drug degradation by digestive enzymes after oral administration, and discomfort associated with parentral drug administration can be avoided by this route. For transdermal delivery of drugs, stratum corneum is the main barrier layer for permeation of drug moiety and act as a rate limiting barrier for penetration of drugs. Hence to increase the permeation of drug through skin membrane, different approaches of penetration enhancements are used. Drugvehicle based enhancement methods such as pro drugs, ion-pair, chemical potential of drug, eutectic systems, complexation and vesicular systems are used in transdermal research as better alternative method to enhance permeation of drugs through skin ${ }^{1}$.

Vesicular systems such as liposomes and niosomes are promising systems to enhance the drug delivery through the skin. They may act as vehicles or as permeation enhancers for drugs to enhance their penetration via stratum corneum. Furthermore, they can be used as controlled percutaneous drug delivery vehicles. The applicability of these vesicular systems is, however, limited because of their stability problems. To overcome the limitations of vesicular drug delivery, proniosomal approach was introduced, which involved a dry product or a liquid crystalline gel that could be hydrated immediately before use and would avoid many of the problems associated with niosomal dispersion and problems of physical stability. Proniosomes are nonionic based surfactant vesicles used to enhance drug delivery in addition to conventional niosomes. There are a number of formulation approaches to resolve the problems of low solubility and low bioavailability. Proniosome technology offers novel solution for poorly soluble drugs ${ }^{2}$.

Candesartan cilexetil (CC) is an esterified prodrug of candesartan, a non-peptide angiotensin II receptor antagonist used in the treatment of hypertension. This medication is also used to treat congestive heart failure. This drug may also be used to help protect the kidneys from damage due to diabetes. The major drawback in the therapeutic application and efficacy of Candesartan cilexetil as an oral dosage form is its very low aqueous solubility $(0.003 \mathrm{mg} / \mathrm{mL})$ and very low oral bioavailability i.e. only $15 \%^{3}$.

Some efforts have been made to enhance the solubility of candesartan cilexetil to study its effect on the bioavailability of the drug. A self emulsifying drug delivery systems (SEDDS) have been developed by M. Sunitha Reddy et al ${ }^{4}$ to enhance the solubility, diffusion rate and oral bioavailability of candesartan cilexetil. The solubility of candesartan cilexetil in different media Tween 80, Sodium dodecyl sulfate, Macrogol 6000, Sodium carboxymethyl cellulose and Sodium carboxymethyl dextran has been reported by Eliska Vaculikova et al ${ }^{5}$.Fast dissolving tablets of 
Candesartan cilexetil by using Novel co-processed superdisintegrants have been developed by S.B. Shirsand et $\mathrm{al}^{6}$ to increase the solubility and dissolution rate of drug.

The aim of this study is to investigate the feasibility of formulation of proniosomes of Candesartan cilexetil. Vesicles prepared were characterized by optical, scanning electron microscopy for vesicle formation and morphology. Drug encapsulation efficiency and release studies were carried out. Finally, a stability study of proniosomal formulations was also performed to investigate the leaking of the drug during storage.

\section{MATERIALS AND METHODS:}

\section{Materials}

Candesartan cilexetil was obtained as gift sample from Hetero pharmaceuticals (Hyderabad). Span 60, Span 40, Span 20 and Span 80 were procured from Loba chemical pvt. Ltd, Mumbai. Tween 20,tween 80 and Cholesterol were procured from SD. fine. chemicals limited, Mumbai. Soya lecithin was procured from $\mathrm{Hi}$ media laboratories PV..Ltd. Mumbai. Absolute ethanol and Potsium dihydrogen phosphate were procured from Merck-specialities pvt. Ltd,Mumbai. Sodium hydroxide was purchased from Thermo fischer scientific india pvt.Ltd, Mumbai.

\section{Drug - Excipients Compatability studies by FT-IR spectroscopy}

Fourier-transform infrared (FTIR) spectrophotometer was used for infra-red analysis of samples to interpret the interactions of drug with non-ionic surfactants and other ingredients. The powdered samples were used for FTIR studies. Infrared (IR) spectra were obtained on a Bruker 1.2.4 IR system (software OPUS 7.0) using the
Attenuated Total Reflectance Spectroscopy method. The scanning range was $400-4000 \mathrm{~cm}-1$. The FT-IR spectra of drug with Non- ionic surfactants, soya lecithin and cholesterol blends were compared with the FT-IR spectrum of pure drug.

\section{Solubility studies}

The solubility of Candesartan cilexetil was determined in water and different $\mathrm{pH}$ buffers (phosphate buffer of $\mathrm{pH} 6.5, \mathrm{pH} 6.8$ and $\mathrm{pH}$ 7.4) and phosphate buffer of $\mathrm{pH}$ 6.5 containing different amount of solubilizer $(0.3 \%$, $0.35 \%, 0.4 \%, 0.5 \%$ and $0.7 \%$ tween 20 ) and the results revealed that, solubility of Candesartan cilexetil was more in phosphate buffer of $\mathrm{pH} 6.5$ containing $0.35 \%$ tween 20 .

\section{Preparation of Transdermal proniosomal gel}

Proniosomal gel of candesartan cilexetil was prepared by coacervation phase separation technique. Drug and required quantities of materials viz surfactant, soya lecithin and cholesterol as per the specified ratio were taken in a dry, clean, wide mouthed test tube. A measured amount of ethanol (absolute alcohol) was added to test tube to dissolve the ingredients. The open end of test tube was covered with a lid to prevent loss of solvent from it and warmed over water bath at $60-70^{\circ} \mathrm{C}$ for about 5 minute until the surfactant mixture was dissolved completely. Then the aqueous phase (phosphate buffer of pH 6.5 containing $0.35 \%$ tween 20) was added and warmed on a water bath till a clear solution was formed. The clear solution formed was cooled to room temperature to convert it to a gel known as Proniosomal gel. The gel obtained was preserved in the same glass tube in a dark for characterization ${ }^{7}$.Composition of proniosomal gel formulations were given in Table 1.

Table 1: Composition of proniosomal gel formulations of candesartan cilexetil

\begin{tabular}{|c|c|c|c|c|c|c|c|c|c|c|c|c|}
\hline \multirow[t]{2}{*}{ Ingredients } & \multicolumn{12}{|c|}{ FORMULATION CODE } \\
\hline & $\begin{array}{l}\text { PN } \\
\text { F1 }\end{array}$ & $\begin{array}{l}\text { PNF } \\
2\end{array}$ & $\begin{array}{l}\text { PNF } \\
3\end{array}$ & $\begin{array}{l}\text { PNF } \\
4\end{array}$ & $\begin{array}{l}\text { PNF } \\
5\end{array}$ & $\begin{array}{l}\text { PNF } \\
6\end{array}$ & $\begin{array}{l}\text { PNF } \\
7\end{array}$ & $\begin{array}{l}\text { PNF } \\
8\end{array}$ & $\begin{array}{l}\text { PNF } \\
9\end{array}$ & $\begin{array}{l}\text { PNF1 } \\
0\end{array}$ & $\begin{array}{l}\text { PNF1 } \\
1\end{array}$ & $\begin{array}{l}\text { PNF1 } \\
2\end{array}$ \\
\hline $\begin{array}{l}\text { Candesartan } \\
\text { cilexitil (mg) }\end{array}$ & 20 & 20 & 20 & 20 & 20 & 20 & 20 & 20 & 20 & 20 & 20 & 20 \\
\hline Span 60(mg) & 180 & - & - & - & - & - & 180 & - & - & - & - & - \\
\hline Span 40(mg) & - & 180 & - & - & - & _- & - & 180 & - & _- & _- & _- \\
\hline Span 20(mg) & _ & _ & 180 & _ & _- & _ & _- & _ & 180 & _ & _ & _ \\
\hline Span 80(mg) & _- & _- & - & 180 & - & - & - & _- & _- & 180 & - & _- \\
\hline Tween $20(\mathrm{mg})$ & _- & _- & _- & - & 180 & _ & - & _- & - & - & 180 & _- \\
\hline Tween 80 (mg) & - & - & - & - & - & 180 & - & - & - & - & - & 180 \\
\hline $\begin{array}{l}\text { Soya } \\
\text { lecithin(mg) }\end{array}$ & 180 & 180 & 180 & 180 & 180 & 180 & 180 & 180 & 180 & 180 & 180 & 180 \\
\hline Cholesterol(mg) & 20 & 20 & 20 & 20 & 20 & 20 & 40 & 40 & 40 & 40 & 40 & 40 \\
\hline Ethanol(ml) & 0.4 & 0.4 & 0.4 & 0.4 & 0.4 & 0.4 & 0.4 & 0.4 & 0.4 & 0.4 & 0.4 & 0.4 \\
\hline $\begin{array}{l}\text { Phosphate } \\
\text { buffer of pH } 6.5 \\
\text { containing } \\
0.35 \% \text { tween } 20 \\
\text { (ml) }\end{array}$ & 0.2 & 0.2 & 0.2 & 0.2 & 0.2 & 0.2 & 0.2 & 0.2 & 0.2 & 0.2 & 0.2 & 0.2 \\
\hline
\end{tabular}




\section{Characterization of Proniosomal gel}

\section{Physical appearance of proniosomal gel ${ }^{8}$}

The prepared gel was viewed through naked eye to characterize color and physical state of gel. Proniosomal gel was also viewed by optical microscope at $40 \mathrm{X}$ magnification, to observe crystal characteristics of gel by spreading as a thin layer on a slide and placing the cover slip on it. The appearance of each formulation was checked for its color, consistency and fluidity.

\section{Vesicle Size Analysis 9}

Size and size distribution studies were done for niosomes obtained after hydration of proniosomal gel with agitation (shaking) and without agitation. Size analysis was done by adding $10 \mathrm{ml}$ of phosphate buffer of $\mathrm{pH} \quad 6.5$ containing $0.35 \%$ tween 20 to the proniosomal gel $(100 \mathrm{mg})$ in a small glass vial with occasional shaking for $10 \mathrm{~min}$. After hydration, the dispersion of niosomes was observed under optical microscope at 40x magnification. The sizes of 100 vesicles were measured using a calibrated ocular and stage micrometer fitted in a optical microscope.

\section{Vesicle morphology ${ }^{10}$}

Shape and surface morphology of proniosomes was studied using scanning electron microscopy (SEM). The niosomes formed from the hydration of proniosomal gel were mounted on an aluminum stub with double-sided adhesive carbon tape. The vesicles were then sputter-coated with gold/palladium using a vacuum evaporator and examined with the scanning electron microscope equipped with a digital camera at $10 \mathrm{kV}$ accelerating voltage.

\section{pH determination ${ }^{11}$}

The proniosomal gel was made into niosomal suspension. Then the $\mathrm{pH}$ of niosomal suspension was determined using $\mathrm{pH}$ meter.

\section{Drug encapsulation efficiency determination ${ }^{12}$}

Proniosomal gel $(0.2 \mathrm{~g})$ was reconstituted with $10 \mathrm{ml}$ of phosphate buffer of $\mathrm{pH} 6.5$ containing $0.35 \%$ tween 20 in a glass tube. The aqueous suspension was sonicated in a bath sonicator for $15 \mathrm{~min}$. The candesartan cilexetil containing niosomes were separated from unentrapped drug by centrifugation at $15000 \mathrm{rpm}$ at $20^{\circ} \mathrm{C}$ for $90 \mathrm{~min}$. The supernatant was taken and diluted with phosphate buffer of $\mathrm{pH} 6.5$ containing $0.35 \%$ tween 20 and the free drug concentration in the resulting solution was assayed by UV spectroscopic method at $257 \mathrm{~nm}$. The percentage of drug encapsulation was calculated by using the following equation.

$$
\operatorname{EP}(\%)=\left[\left(c_{t}-c_{r}\right) / c_{t}\right] \times 100
$$

Where EP is the encapsulation percentage, $C \mathrm{t}$ is the concentration of total drug, and $\mathrm{Cr}$ is the concentration of free drug.

\section{In-Vitro drug diffusion study ${ }^{13}$}

The in-vitro release studies on proniosomal gel were performed using Franz-diffusion cell. The capacity of receptor compartment was $10 \mathrm{ml}$. The area of donor compartment exposed to receptor compartment was 1.88 $\mathrm{cm}^{2}$. The membrane was mounted between the donor and receptor compartment. A weighed amount of proniosomal gel equivalent to $20 \mathrm{mg}$ drug was placed on one side of the membrane. $10 \mathrm{ml}$ of phosphate buffer of $\mathrm{pH} 6.5$ containing $0.35 \%$ tween 20 was taken as receptor medium. The receptor compartment was surrounded by a water jacket to maintain the temperature at $37 \pm 1^{\circ} \mathrm{C}$. The receptor fluid was stirred by a Teflon-coated magnetic bead fitted to a magnetic stirrer at a speed of $600 \mathrm{rpm}$. Samples were withdrawn at regular intervals ( $1,2,3,4,5,6,7,8,9,10,11,12$, and 24 h). At each sampling interval, $1 \mathrm{ml}$ samples were withdrawn and were replaced by equal volumes of fresh receptor fluid. Sink condition was maintained throughout the experiment. Samples withdrawn were suitably diluted and analyzed spectrophotometrically at $257 \mathrm{~nm}$.

\section{Release kinetics $^{14}$}

To study the release kinetics, data obtained from in vitro diffusion studies was fitted in various kinetic models: zero order as cumulative percent of drug release vs. time, first order as log cumulative percentage of drug remaining vs. time, Higuchi's model as cumulative percent of drug release vs. square root of time and Erosion model as cubic root of the unreleased fraction of the drug versus time. To determine the mechanism of drug release, the data was fitted into Korsmeyer and Peppas equation as log cumulative percentage of drug released vs. log time, and the exponent $\mathrm{n}$ was calculated from slope of the straight line. The value of $n$ characterizes the release mechanism of drug, if exponent is 0.5 , then diffusion mechanism is fickian; if $0.5<n$ $<0.89$, mechanism is non- fickian, $n=1$ to Case II (relaxational) transport, and $n>1$ to super case II transport.

\section{Preparation of wistar rat skin for permeation studies $^{1,11,15}$}

In the present study, wistar albino rat abdominal skin was used. Ex vivo skin permeation studies were carried out with Institutional Animal Ethical Committee approval (Approval Number: HCOP/IAEC/2013-14/01). After the animal was sacrificed, the abdominal skin was shaved lightly with an electrical clipper (before of which a depilatory cream was applied) taking care to prevent any damage to the surface of the skin, then the abdominal skin was excised from the animal using a sharp blade and surgical scissors. The skin was lifted easily from the animal after incision was made. The skin was defatted by wiping it with a cotton tip soaked in diethyl ether to remove the subcutaneous fat and scraping the dermal side to remove the muscle and blood vessels. The skin was wiped again with a cotton tip soaked in ether to prevent any adhering fat. The skin so prepared was wrapped in aluminium foil and stored in a deep freezer at $\left(2-5^{\circ} \mathrm{C}\right)$ till further use. The skin was defrosted at room temperature when required.

\section{Ex-Vivo drug permeation studies}

The selected formulations on the basis of entrapment efficiency, and in vitro drug release were subjected to ISSN: 2250-1177

CODEN (USA): JDDTAO 
permeation studies through rat skin using Franz Diffusion cell. Before starting the experiment, the skin was kept in phosphate buffer $\mathrm{pH} 7.4$ for about 1 hour in a water bath at constant temperature of $37^{\circ} \mathrm{C}$ to allow water soluble UV absorbing material to leach out. The effective permeation area of the diffusion cell was 1.88 $\mathrm{cm}^{2} .10 \mathrm{ml}$ of phosphate buffer of $\mathrm{pH} 6.5$ containing $0.35 \%$ tween 20 was taken as receptor medium. Excised skin was mounted between the donor and the receptor compartment with stratum corneum side facing upwards into the donor compartment. The donor compartment was left open and wrapped with cellophane to prevent contamination of the formulation from the atmosphere, A weighed amount of proniosomal gel equivalent to $20 \mathrm{mg}$ drug was placed on the surface of the skin. Temperature was maintained at $37 \pm 1^{\circ} \mathrm{C}$ using water bath. The receptor chamber contents were magnetically stirred at $600 \mathrm{rpm}$. Samples were withdrawn at regular intervals $(1,2,3,4,5,6,7,8,9,10,11,12$, and $24 \mathrm{~h})$, and analyzed for drug content spectrophotometrically at 257 $\mathrm{nm}$. Cumulative amount of drug permeated through the skin $\left(\mu \mathrm{g} / \mathrm{cm}^{2}\right)$ was plotted as a function of time $(t)$ for each formulation.

The skin flux $(J)\left(\mu \mathrm{g} / \mathrm{cm}^{2} / \mathrm{h}\right)$, was determined from the slope of linear portion of the cumulative amount permeated per unit area versus the time plot. Permeability coefficient $(\mathrm{Kp})(\mathrm{cm} / \mathrm{h})$, was calculated by dividing $\mathbf{J}$ with the concentration of the drug in donor cell $\left(C_{0}\right)$ by using the following equation:

$$
\mathbf{K p}=\mathbf{J} / \mathbf{C}_{\mathbf{0}}
$$

The skin flux can be experimentally determined from the following equation $\mathbf{J}=(\mathbf{d Q / d t}) / \mathbf{A}$ where $\mathrm{J}$ is flux ( $\mu \mathrm{g} / \mathrm{cm}^{2}$ per $\left.\mathrm{h}\right), \mathrm{A}$ : Area of skin tissue $\left(\mathrm{cm}^{2}\right)$ through which drug permeation takes place, $(\mathrm{dQ} / \mathrm{dt})$ is the slope.

\section{Short term stability studies ${ }^{16}$}

Stability studies were conducted for the best formulation i.e. PNF7 of candesartan cilexetil proniosomal gel. The ability of vesicles to retain the drug (Drug Retention Behaviour) was assessed by keeping the proniosomal gel at three different temperature conditions, i.e., refrigeration temperature $\left(4-8^{0} \mathrm{C}\right)$, room temperature $\left(25 \pm 2^{\circ} \mathrm{C}\right)$ and oven maintained at $\left(45 \pm 2^{\circ} \mathrm{C}\right)$. Throughout the study, proniosomal formulation was stored in aluminium foil-sealed glass vials. The stored formulation was analyzed for particle size \& percent drug entrapment.

\section{RESULTS AND DISCUSSIONS}

\section{Drug - Excipients Compatability studies}

The FTIR spectra of pure candesartan cilexetil and physical mixture of drug with excipient is shown in Fig. 1(a),(b). The presence of peaks at $2932.65 \mathrm{~cm}^{-1}$ (Aromatic C-H stretching), $1115.95 \mathrm{~cm}^{-1} \quad$ (C-N stretching), $3610.80 \mathrm{~cm}^{-1}$ (N-H stretching), $1752.10 \mathrm{~cm}^{-}$ ${ }^{1}\left(\mathrm{C}=\mathrm{O}\right.$ stretching), $746.98 \mathrm{~cm}^{-1}$ (Aromatic $\mathrm{C}-\mathrm{H}$ bending), $2858.18 \mathrm{~cm}^{-1}$ (Aliphatic C-H stretching), $1241.41 \mathrm{~cm}^{-1}$ (C-O-C) were characteristic to the pure candesartan cilexetil. IR spectrum of physical mixture of drug with excipients revealed that there was no appreciable change in position and intensity of peak with respect to IR spectrum of pure candesartan cilexetil. IR analysis revealed that there was no known chemical interaction between drug and excipients.

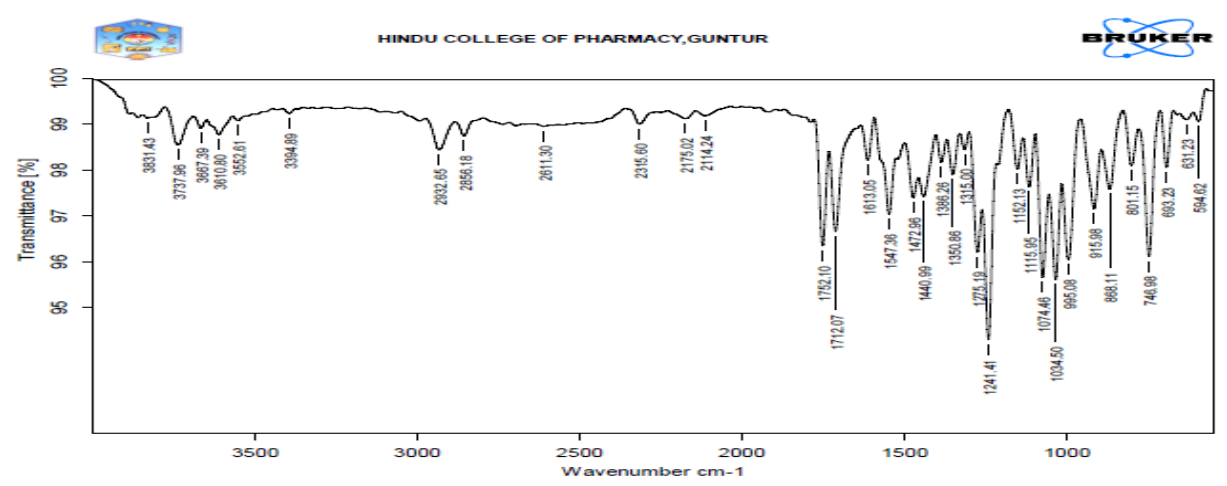

Fig 1(a): FT-IR spectrum of pure drug candesartan cilexetil

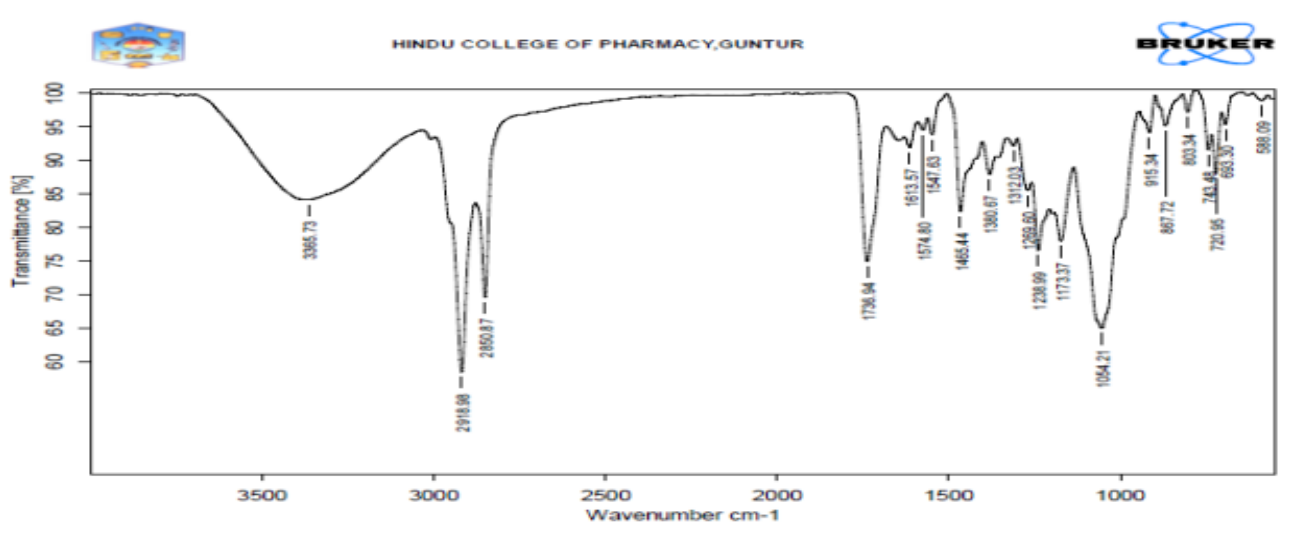

Fig 1(b): FT-IR spectrum of physical mixture of drug 


\section{Vesicle morphology}

The morphology of niosomes derived from proniosomal gel was studied using Scanning Electron Microcopy. SEM imaging of candesartan cilexetil revealed that the niosomes produced from hydration of proniosomes were spherical in shape and discrete with sharp boundaries having large internal aqueous space. SEM imaging of niosome produced from optimized formulation PNF7 was shown in Fig 2. The optical microscopy images of the niosomes prepared from different proniosomal formulations are shown in Fig 3.

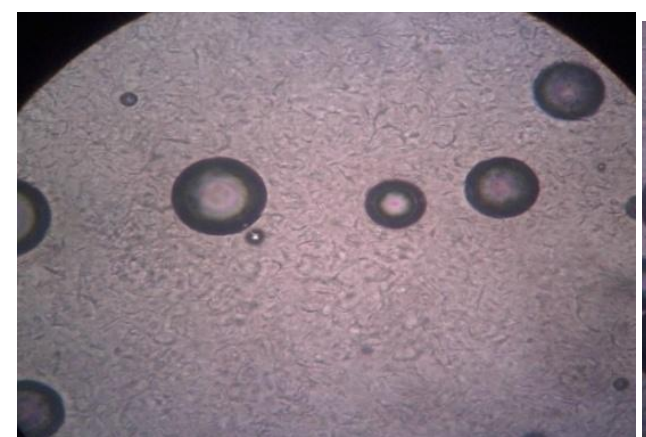

(a)

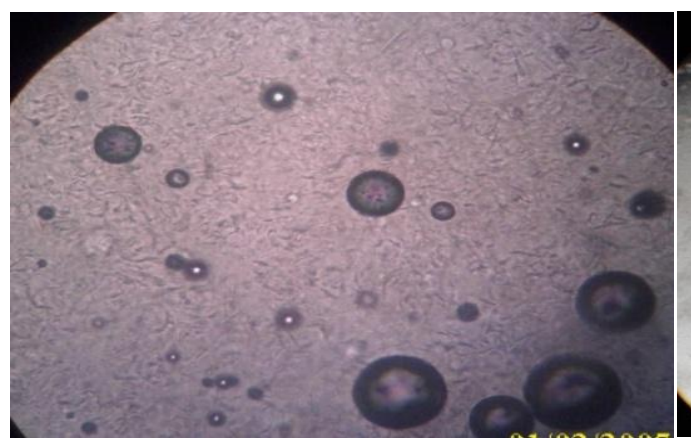

(c)

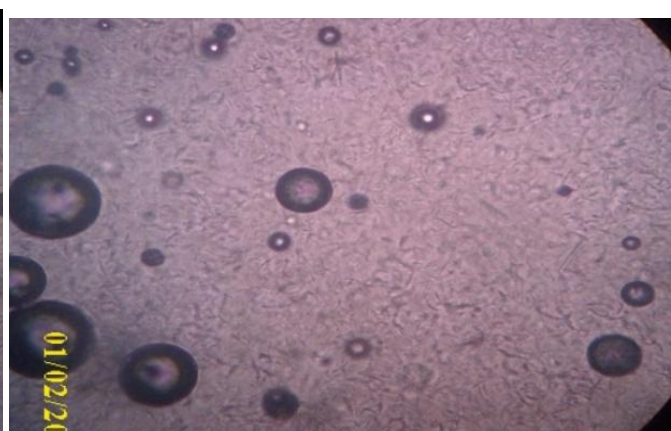

(b)

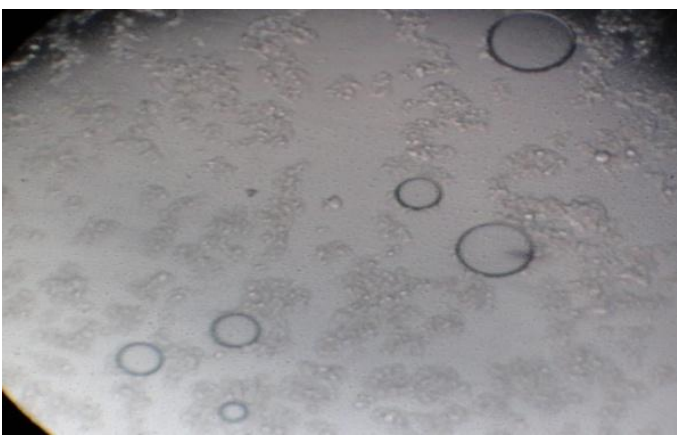

(d)

Fig $3(a),(b),(c),(d)$ : Optical microscopic images of proniosomal gel formulations

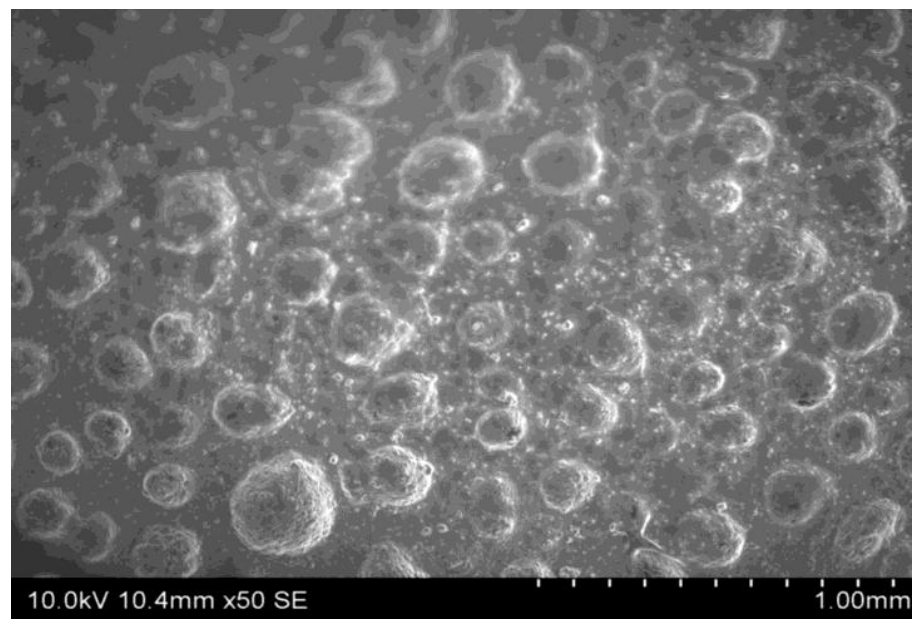

Fig 2: SEM images of optimised formulation (PNF7)

\section{Physical appearance of proniosomal gel}

Proniosomal gel of candesartan cilexetil prepared with Span (40, 60) have pale yellow semi solid gel like appearance. Proniosomal gel produced from Span 20 have thick sticky gel like appearance and span 80 have light brownish gel like appearance. Proniosomal gel of tween 20 appears as Yellow highly viscous liquid form and proniosomal gel of Tween 80 appears as semisolid crystalline gel. The results are reported in Table 2 .

\section{Vesicle size analysis}

Mean Vesicle size of candesartan cilexetil proniosomes was presented in Table 2, which indicated that vesicles formed with Spans were smaller in size than vesicles formed with Tweens. The relationship 
observed between niosome size and Span hydrophobicity has been attributed to the decrease in surface energy with increasing hydrophobicity, resulting in the smaller vesicles. This would also explain the large vesicle size of niosomes prepared with Tween which has a much lower hydrophobicity than Span. Increasing the cholesterol content also contributed an increase in the hydrophobicity, with a subsequent slight reduction in vesicle size. The differences in vesicle size among the niosomes prepared with Span were not significant. The Size of vesicle was reduced when dispersion was agitated due to breakage of larger vesicles to smaller vesicles.

\section{pH determination}

Skin compatibility is the primary requirement for a good topical formulation. It was found that the $\mathrm{pH}$ of all the formulations were in the range of 5.64 to 7.20, which suits the skin $\mathrm{pH}$, indicating skin compatibility. The results of $\mathrm{pH}$ determination are reported in Table 2.

\section{Drug encapsulation efficiency}

Encapsulation efficiency of proniosomal gel formulations ranged from $80.40 \%$ to $92.20 \%$. The drug encapsulation efficiency of twelve formulations were shown in Table 2.and Fig 4.
As shown in Table 2, Encapsulation efficiency of proniosomes formed from Span 60, Span 40, Span20, and Span 80 was found high compared with proniosomes prepared from Tweens (Tween 20, Tween 80). Among the spans, Span 60 have higher encapsulation efficiency due to the longer saturated alkyl chain compared to that of span 40,span 20 and span 80.Most of the surfactants used to make nonionic surfactant vesicles such as spans have a low aqueous solubility. However, freely soluble nonionic surfactants such as Tween can form the micelles on hydration in the presence of cholesterol. The tween formulations in the present study were also able to entrap candesartan cilexetil efficiently. However the encapsulation efficiency was relatively low compared to those composed of Span. This is because the vesicles can be successfully formed by Tween only in the presence of excess cholesterol.

As the cholesterol content of the formulation increased, the encapsulation of drug also increased. The formulations (PNF7-PNF12) containing 9:9:2 ratio of surfactant : soya lecithin : cholesterol showed high encapsulation efficiency compared to the formulations (PNF1-PNF6) containing 9:9:1 ratio of surfactant:soya lecithin :cholesterol.

Table 2: Characterization of proniosomal formulations for physical appearance, $\mathrm{pH}$, Vesicle size and Encapsulation Efficiency.

\begin{tabular}{|c|c|c|c|c|c|}
\hline \multirow{2}{*}{$\begin{array}{l}\text { Formulation } \\
\text { code }\end{array}$} & \multirow[t]{2}{*}{ Physical appearance } & \multirow[t]{2}{*}{ pH } & \multicolumn{2}{|c|}{ Mean vesicle size $(\mu \mathrm{m})$} & \multirow{2}{*}{$\begin{array}{c}\text { Encapsulation } \\
\text { efficiency* }\end{array}$} \\
\hline & & & $\begin{array}{l}\text { Without } \\
\text { agitation* }\end{array}$ & $\begin{array}{c}\text { With } \\
\text { agitation* }\end{array}$ & \\
\hline PNF1 & Pale yellow semi solid gel & 5.89 & $25.06 \pm 0.50$ & $5.97 \pm 0.55$ & $85.83 \pm 0.67$ \\
\hline PNF2 & Pale yellow semi solid gel & 5.97 & $24.89 \pm 0.40$ & $6.54 \pm 0.67$ & $87.65 \pm 0.47$ \\
\hline PNF3 & Yellow semisolid thick sticky gel & 6.2 & $19.82 \pm 0.16$ & $9.48 \pm 0.77$ & $85.79 \pm 0.85$ \\
\hline PNF4 & Light Brownish gel & 6.6 & $17.41 \pm 0.94$ & $7.57 \pm 0.11$ & $84.08 \pm 0.32$ \\
\hline PNF5 & Yellow highly viscous liquid & 5.82 & $22.50 \pm 0.58$ & $8.5 \pm 0.23$ & $82.45 \pm 0.45$ \\
\hline PNF6 & Yellow semisolid crystalline gel & 7.1 & $20.95 \pm 0.96$ & $10.64 \pm 0.89$ & $80.40 \pm 0.87$ \\
\hline PNF7 & Yellowish semisolid gel & 6.80 & $24.65 \pm 0.12$ & $4.27 \pm 0.43$ & $92.29 \pm 0.56$ \\
\hline PNF8 & Yellowish semisolid gel & 6.30 & $22.58 \pm 0.19$ & $5.54 \pm 0.38$ & $90.21 \pm 0.98$ \\
\hline PNF9 & Yellow semisolid thick sticky gel & 5.64 & $20.62 \pm 0.86$ & $7.98 \pm 0.92$ & $89.56 \pm 0.22$ \\
\hline PNF10 & Light Brownish gel & 7.2 & $18.56 \pm 0.54$ & $6.19 \pm 0.45$ & $86.24 \pm 0.34$ \\
\hline PNF11 & Brownish semisolid compact mass & 6.7 & $16.22 \pm 0.84$ & $7.2 \pm 0.67$ & $84.18 \pm 0.73$ \\
\hline PNF12 & Yellow semisolid crystalline gel & 6.56 & $19.45 \pm 0.26$ & $9.28 \pm 0.87$ & $82.65 \pm 0.99$ \\
\hline
\end{tabular}

*All values represent mean \pm standard deviations $(S D), n=3$ 


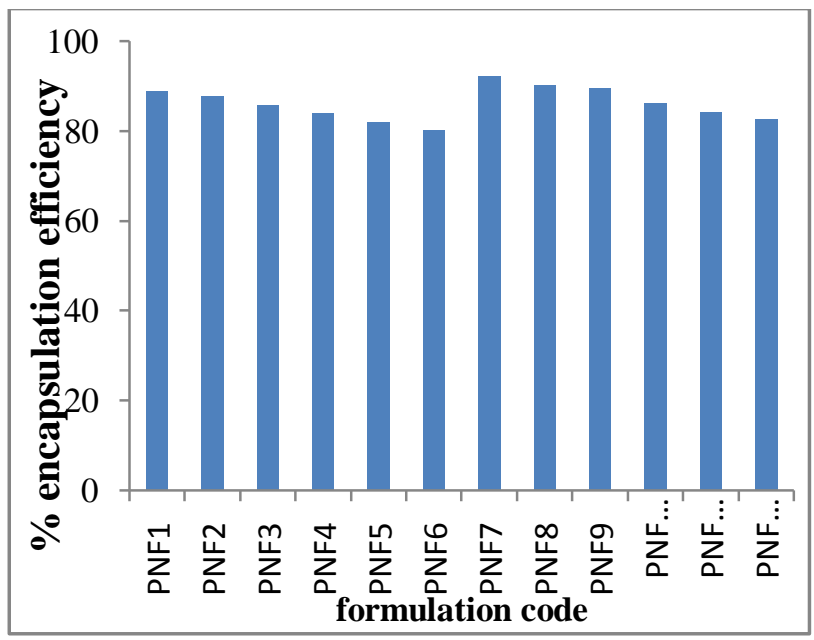

Fig 4: Comparision of entrapment efficiency of proniosomal gel formulations

\section{In vitro drug diffusion studies}

The results indicated, that PNF1 containing span 60 had shown higher drug release profile than other formulations, because niosomes prepared with tweens and other spans were significantly larger than those prepared with Span60. Proniosomes of Span 60 were smaller in size, demonstrated higher hydrophobicity and higher surface area due to low vesicle size and hence better permeability of drug has occured. Higher drug permeation was seen from niosomes prepared with Span 60 than from the other surfactant. This could be due to the emulsification effect of the surfactant after the hydration of the proniosome by the diffusion medium and formation of channels within the gel structure due to loss of lipid bilayer. Drug released from proniosomes prepared with tweens showed lesser extent of drug release compared to that prepared with span. It might be due to the larger size of the vesicles and less lipophilic nature of the Tween, which makes it more difficult for these vesicles to penetrate or fuse with membrane whereas the inclusion of Span which is more lipophilic than Tween further increased the lipophilicity of the drug leading to better penetration.

Formulations which have higher cholesterol content (PNF7-PN12) showed less drug release over a period of $24 \mathrm{hrs}$. Increase in cholesterol ratio resulted in a more intact lipid bilayers as a barrier for drug release and decreased its leakage by improving the fluidity of the bilayers membrane and reducing its permeability, which led to lower drug elution from the vesicles.

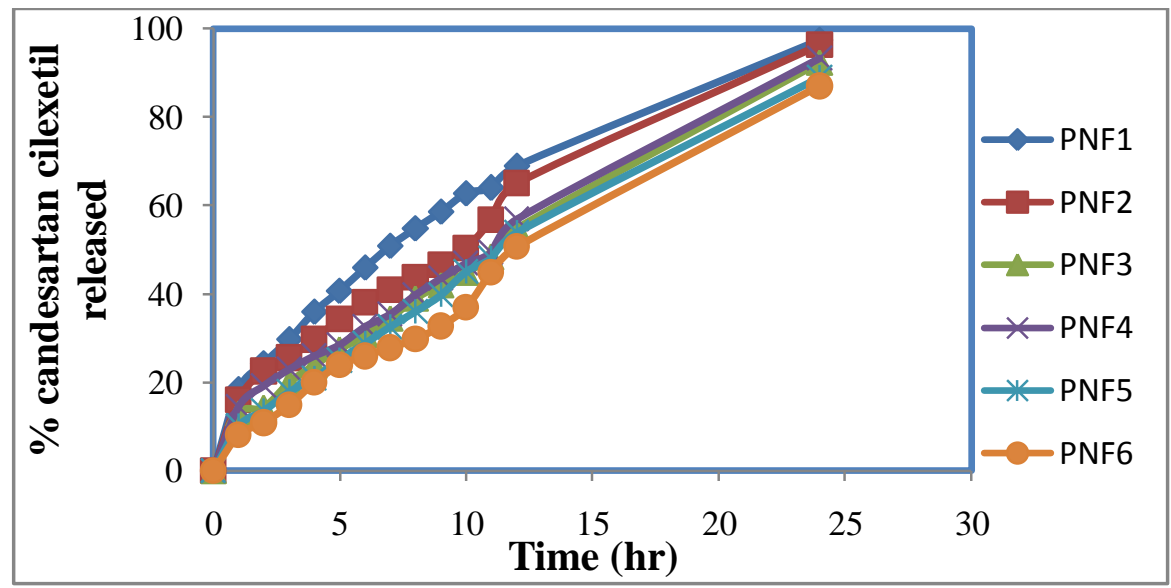

Fig. 5: In vitro drug release profiles of candesartan cilexetil from PNF1-PNF6 proniosomal gel formulations

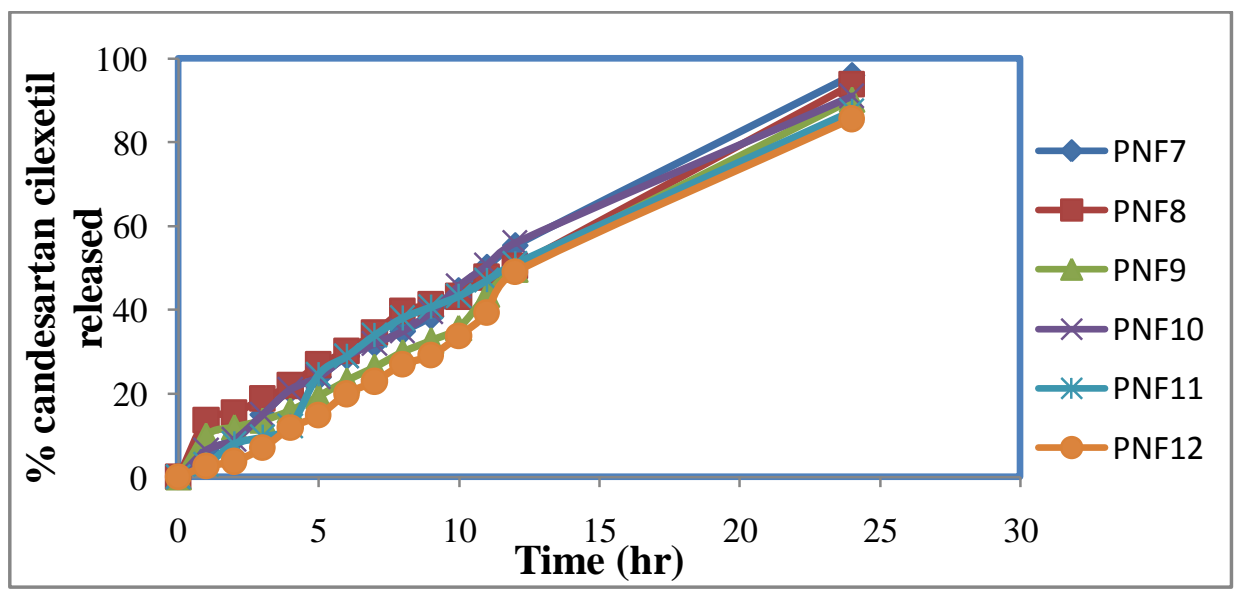

Fig. 6: In vitro drug release profiles of candesartan cilexetil from PNF7-PNF12 proniosomal gel formulations 


\section{In vitro drug release kinetics}

In vitro drug release profile of each formulation was fitted in to different equations and kinetic models to explain the release kinetics of candesartan cilexetil from proniosomal gel. When the $\mathrm{R}^{2}$ values of regression plots for first order and zero order were considered, $\mathrm{R}^{2}$ values of zero order plots were found to be higher than first order plots. Hence it is evident that the drug release from all candesartan cilexetil proniosomal gel formulations, followed zero order kinetics. By incorporating release data in Higuchi and Erosion models, the $\mathrm{R}^{2}$ values of all the formulations were found to be greater for higuchi model. So all the formulations in this study were best expressed by higuchi's classical diffusion equation. The linearity of plot indicated that the release process was diffusion controlled. To further confirm the exact mechanism of drug release, the data was incorporated in to kores meyer peppas model and the mechanism of drug release was indicated according to the value of exponent ' $n$ '. For all the proniosomal gel formulations the release exponent ' $n$ ' value found to be between 0.5 to 0.89 . This indicates the drug released from all the proniosomal gel formulations followed non-fickian diffusion. In vitro drug release data was best fitted in higuchi and kores -meyer peppas equation showing that the drug release was controlled mainly by diffusion mechanism.

\section{Ex-Vivo drug permeation studies}

The ex vivo permeation of Candesartan cilexetil through rat abdominal skin from proniosomal gel formulations was determined using Franz diffusion cell. Six proniosomal gel formulations were selected based on high encapsulation efficiency and in vitro drug release. The selected proniosomal formulations (PNF1, PNF2, PNF4, PNF7, PNF8, PNF10) were characterized for their drug permeation through rat abdominal skin. The cumulative amount of candesartan cilexetil permeated per unit area across excised rat skin as the function of time, flux and permeability coefficient were determined.

Increasing the cholesterol content resulted in a more intact lipid bilayer as a barrier for drug permeation and decreased its leakage by improving the fluidity of the bilayer membrane and reducing its permeability, which led to lower drug elution from the vesicles. Among all the formulations, PNF1 showed higher drug permeation $81.3 \pm 0.76 \%$ in $24 \mathrm{hrs}$ with a flux value of $1.90 \pm 0.13$ $\mu \mathrm{g} / \mathrm{cm}^{2} / \mathrm{hr}$ and permeability coefficient of $0.095 \pm 0.18$ $\mathrm{cm}^{2} / \mathrm{hr}$.

Table 3. Flux and Permeability co efficient of Candesartan cilexetil proniosomal gel formulations

\begin{tabular}{|c|c|c|}
\hline $\begin{array}{c}\text { Formulation } \\
\text { code }\end{array}$ & Flux $\left(\boldsymbol{\mu g} / \mathbf{c m}^{\mathbf{2}} / \mathbf{h r}\right)^{*}$ & $\begin{array}{c}\text { Permeability coefficient } \\
\left.\mathbf{c m}^{\mathbf{2}} / \mathbf{h r}\right)^{*}\end{array}$ \\
\hline PNF1 & $1.90 \pm 0.13$ & $0.095 \pm 0.17$ \\
\hline PNF2 & $1.87 \pm 0.19$ & $0.088 \pm 0.16$ \\
\hline PNF4 & $1.84 \pm 0.17$ & $0.087 \pm 0.13$ \\
\hline PNF7 & $1.89 \pm 0.09$ & $0.094 \pm 0.18$ \\
\hline PNF8 & $1.84 \pm 0.12$ & $0.092 \pm 0.15$ \\
\hline PNF10 & $1.79 \pm 0.15$ & $0.089 \pm 0.11$ \\
\hline \multirow{2}{*}{ * All values represent mean \pm standard deviations $(S D), n=3$}
\end{tabular}

\section{Short term Stability studies}

Short term Stability studies were conducted for the optimised formulation (PNF7) of Candesartan cilexetil proniosomal gel at room temperature $\left(30 \pm 2^{\circ} \mathrm{c}\right)$, at refrigerator temperature $\left(4 \pm 2^{\circ} \mathrm{c}\right)$, and oven maintained at $45 \pm 2^{\circ} \mathrm{c}$ for a period of 2 months. There was no significant change in relation to vesicle size and encapsulation efficiency. The results are given in Table 4.

Table 4. Stability study data of optimized formulation (PNF7)

\begin{tabular}{|l|l|l|l|l|l|}
\hline S.No. & \multirow{2}{*}{ Temp. } & \multicolumn{2}{|l|}{ Initial } & \multicolumn{2}{|l|}{ After 2 months } \\
\cline { 3 - 6 } & & $\begin{array}{l}\text { Vesicle } \\
\text { size* }\end{array}$ & $\begin{array}{l}\text { Encapsulation } \\
\text { efficiency* }\end{array}$ & $\begin{array}{l}\text { Vesicle } \\
\text { size* }\end{array}$ & $\begin{array}{l}\text { Encapsulation } \\
\text { efficiency* }\end{array}$ \\
\hline 1 & $4-8^{0} \mathrm{c}$ & $4.27 \pm 0.43$ & $90.60 \pm 0.56$ & $4.37 \pm 0.67$ & $89.01 \pm 0.46$ \\
\hline 2 & $25 \pm 2^{0} \mathrm{c}$ & $4.27 \pm 0.43$ & $90.60 \pm 0.56$ & $4.98 \pm 0.34$ & $86.32 \pm 0.56$ \\
\hline 3 & $45 \pm 2^{0} \mathrm{c}$ & $4.27 \pm 0.43$ & $90.60 \pm 0.56$ & $5.12 \pm 0.95$ & $80.73 \pm 0.32$ \\
\hline
\end{tabular}

* All values represent mean \pm standard deviations $(S D), n=3$ 


\section{CONCLUSION:}

In the present work, an attempt had been made to develop proniosomal gel for transdermal delivery of candesartan cilexetil by using different grades of non ionic surfactants. All the proniosomal gel formulations were evaluated for the vesicle size, shape, encapsulation efficiency, in vitro drug diffusion study, and ex vivo permeation study and the results were found in the acceptable range. Vesicle size was decreased with increasing concentration of cholesterol and

\section{REFERENCES:}

1. Hemant n. patil, sharwaree r. hardikar, ashok v. bhosale formulation development \& evaluation of proniosomal gel of carvedilol, international journal of pharmacy and pharmaceutical sciences, vol 4, issue 1,2012:192-198.

2. Trupti Anil Udasi Proniosome: a novel approach to vesicular drug delivery system International Journal of Pharmacy and Pharmaceutical Science Research 2013; 3(1): 1-6.

3. Asif Husain, Md Sabir Azim, Moloy Mitra and Parminder S. Bhasin, A Review on Candesartan: Pharmacological and Pharmaceutical Profile, Journal of Applied Pharmaceutical Science 01 (10); 2011: 12-17.

4. M. Sunitha Reddy, P. Srinivas Goud and S.S. Apte, Solubility Enhancement of Candesartan cilexetil by Self Emulsifying Drug Delivery Systems, International Journal Of Pharmaceutical Sciences And Research,2012,3(7): 20982104

5. Eliska Vaculikova, Veronika Grunwaldova, Vladimir Kral, Jiri Dohnal and Josef Jampilek , Preparation of Candesartan and Atorvastatin Nanoparticles by Solvent Evaporation, Molecules ,2010,17: 13221-13234.

6. S.B.Shirsand, R.G. Ramani, P.V.Swamy, Novel Coprocessed Superdisintegrant in the Design of Fast Dissolving Tablets, International Journal of Pharmacy and Biological Sciences, 2011(1): 1-12.

7. Kakkar Rishu, Rao Rekha, Dahiya Navin Kumar and Nanda Sanju. Formulation and characterisation of valsartan proniosomes. Maejointernational journal of Science and Technology, 2010,5(01),146-158.

8. Alpana ram, abhinav thakur, vineet $\mathrm{k}$ mittal.,proniosomal provesicular system for transdermal delivery of hydralazine for hypertension asian j pharm clin res, vol 5, issue 3, 2012, 219-225.

9. Ashish Kute, Prakash Goudanavar*, Doddayya Hiremath, S.R. Reddy Development and Characterization of Perindopril encapsulation of drug was increased with increasing concentration of cholesterol but drug release was retarded with increase in concentration of cholesterol. Among all the formulations PNF7 (span 60, soya lecithin, and cholesterol present in 9:9:2 ratio) was selected as an optimised formulation, due to low vesicle size, high encapsulation efficiency, and released the drug in a controlled manner for extended period of time. Overall, these findings indicate that proniosomal gel will be promising drug delivery system for candesartan cilexetil.
Erbumine Loaded Proniosomal Gel, Asian J. Pharm. Tech. 2012; Vol. 2: Issue .2, Pg 54-58.

10. Reena Thakur, Md Khalid Anwer1, Mohammad S. Shams1, Asgar Ali, Roop K. Khar, Faiyaz Shakeel, and Ehab I. Taha et al., Proniosomal transdermal therapeutic system of losartan potassium: development and pharmacokinetic evaluation.Journal of Drug Targeting, 2009; 17(6): 442-449.

11. Alaa A. Abdul Rasool and Haider Kadhum Abbas. Preparation and evaluation a proniosomal gel for terbutaline sulfate as transdermal drug delivery system. Kufa Journal For Veterinary Medical Sciences Vol.(1) No. (1) 2010.78-93.

12. Samita Singla, S.L. Harikumar, Geeta Aggarwal Proniosomes for effective topical delivery of clotrimazole development characterization and performance evaluation Asian Journal of Pharmaceutical Sciences 2012, 7 (4): 259 270

13. Alsarra I A, Bosela AA, Ahmed S.M, Mahrous GM. Proniosomes as a drug carrier for transdermal delivery of ketorolac. European Journal of Pharmaceutics and Biopharmaceutics. 2005; 59(3): 485-490.

14. Yuksel N, Kanik AE, Baykara T. Comparison of in vitro dissolution profiles by ANOVA-based, model-dependent and independent methods. International Journal of Pharmaceutics, 2000; 209: 57-67.

15. M Hanan, S Omar, Novel sugar esters proniosomes for transdermal delivery of Vinpocetine: Preclinial and clinical studies. European Journal of Pharmaceutics and Biopharmaceutics 2011; 77: 43-55.

16. walve jr, bakliwal sr, rane br, gujrathi na, pawar sp. Design, development and evaluation of a proniosomal transdermal drug delivery system for diclofenac, international journal of pharmaceutical invention, may 2012 volume 2(4), 6-15. 